\title{
IMPLEMENTASI KRIPTOGRAFI HIBRID DENGAN ALGORITMA ELGAMAL DAN ALGORITMA ONETIME PAD(OTP) DALAM PENGAMANAN FILE AUDIO BERBASIS DESKTOP
}

\author{
Sri Melvani Hardi ${ }^{(1)}$, Daniel Hamonangan ${ }^{(2)}$, Muhammad Zarlis ${ }^{(3)}$ \\ Program Studi S-1 Ilmu Komputer, Fasilkom-TI USU \\ Jalan Universitas N0.9 Kampus Universitas Sumatera Utara Medan \\ 20155 \\ E-mail : vani.hardi@usu.ac.id ${ }^{(1)}$ \\ danchamp.siregar27@gmail.com ${ }^{(2)}$ \\ m.zarlis@usu.ac.id ${ }^{(3)}$
}

\begin{abstract}
Abstrak
Audio merupakan salah satu cara untuk menyampaikan informasi. Bertukar informasi audio dapat dilakukan dengan mudah pada saat ini. Namun hal ini menyebabkan informasi audio yang bersifat pribadi ataupun rahasia menjadi tidak aman. Maka dari itu diciptakanlah sebuah sistem pada desktop yang mampu mengamankan file audio dengan menggunakan algoritma One-Time Pad dan algoritma ElGamal. Algoritma One-Time Pad merupakan algoritma yang sangat aman dalam mengamankan data audio namun memiliki kerentanan didalam kebocoran informasi kunci maka dibutuhkan algoritma ElGamal yang dapat mencegah kebocoran informasi kunci. Berdasarkan pengujian didapatkan hasil bahwa cepat lambatnya waktu proses enkripsi dan proses dekripsi, dipengaruhi oleh ukuran data file audio .Semakin besar data file audio tersebut maka semakin lambat waktu proses yang dilakukan. Hasil dari sistem ini berupa file audio yang terenkripsi, file kunci OTP terenkripsi yang dapat mengamankan data.
\end{abstract}

Kata Kunci: Kriptografi Audio, Kriptografi Wav File, One-Time Pad, ElGamal.

\section{PENDAHULUAN}

Media audio adalah media yang digunakan untuk menyampaikan pesan yang hanya dapat dimengerti oleh indera pendengaran. Pesan atau informasi yang akan disampaikan dituangkan kedalam lambanglambang auditif yang berupa kata-kata, musik, ataupun sound effect (Riyana, 2009). Media audio dipakai karena mudah dalam 
penggunaannya begitu juga dalam pengakasesannya. Dengan kecanggihan teknologi pada saat ini siapa pun dapat mengakses berbagai macam file audio.

Namun hal ini menyebabkan semakin tidak aman dalam bertukar informasi audio terutama audio yang bersifat rahasia ataupun pribadi yang tidak ingin diketahui orang lain. Maka dari itu perlu dilakukan pengamanan file audio sebelum audio tersebut dikirim untuk menghindari tindak kejahatan terhadap pesan audio yang dikirim.

Salah satu cara untuk menjaga keamanan dan kerahasiaan data suatu file audio adalah menggunakan kriptografi. Kriptografi adalah ilmu dan seni untuk mengamankan dokumen dengan teknik enkripsi sehingga dokumen yang diamankan tidak dapat di mengerti oleh orang lain yang tidak berkepentingan [2].

Ramadayanti (2008) meneliti tentang Analisa algoritma Vernam (OTP). Beliau menyimpulkan bahwa algoritma OTP tidak terpecahkan karena ciphertext yang seluruhnya acak didapatkan dari penjumlahan barisan kunci acak ditambah dengan plaintext yang tidak acak dan jika mendekripsikan cipherteksnya dengan beberapa kunci berbeda dapat menghasilkan plaintext yang bermakna, Namun algoritma ini juga memiliki kelemahan didalam pendistribusian kunci, pertukaran kunci yang terjadi antara pihak pengirim pesan dan penerima pesan merupakan titik rentan dalam metode enkripsi ini, karena kebocoran kunci dapat terjadi pada saat pertukaran informasi.

Riyanto (2007) meneliti tentang pengamanan pesan rahasia menggunakan algoritma kriptografi ElGamal atas grup penggandaan $\mathrm{Zp}^{*}$. Beliau menyimpul- kan bahwa algoritma kriptografi asimetris seperti algoritma kriptografi ElGamal, sangat baik untuk mengatasi masalah pada pendistribusian kunci.

Berdasarkan hasil penelitian diatas penulis hendak melakukan penelitian dengan mengkombinasikan algoritma One-Time Pad dan algoritma ElGamal untuk meningkatkan keamanan pada file audio, dengan judul "Implementasi Kriptografi Hibrid dengan Algoritma ElGamal dan Algoritma One-Time Pad dalam pengamanan file audio berbasis dekstop". 


\section{METODE PENELITIAN}

Masalah dalam penelitian ini ditunjukan pada gambar 1 dibawah ini

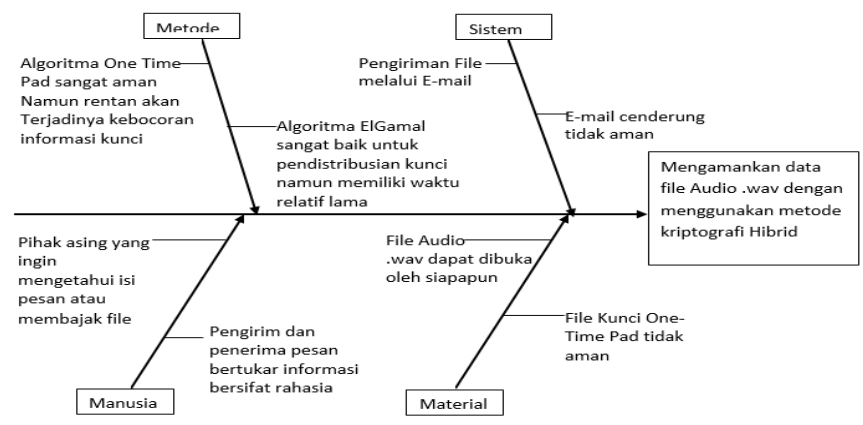

Gambar 2.1. Diagram Ishikawa

Rancangan use case diagram pada penelitian ini ditunjukan pada gambar 2

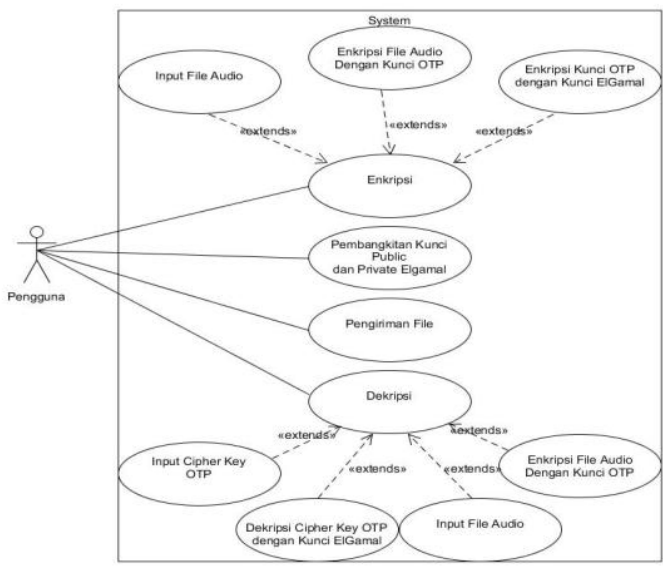

Gambar 2.2Use Case Diagram

Flowchart merupakan diagram yang menggunakan simbol-simbol untuk menggambarkan urutan langkah kerja secara berurutan dan sistematis.

Berikut adalah flowchart enkripsi dan dekripsi pada sistem yang dapat dilihat pada gambar 3 dan gambar 4.' 

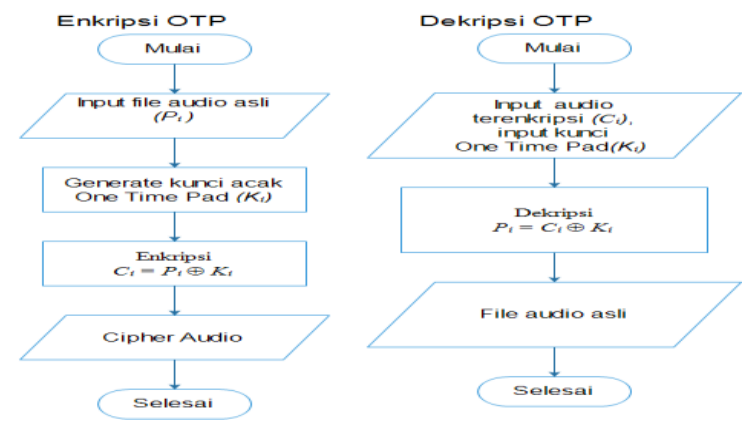

Gambar 2.3.Flowchart Enkripsi Dekripsi OTP
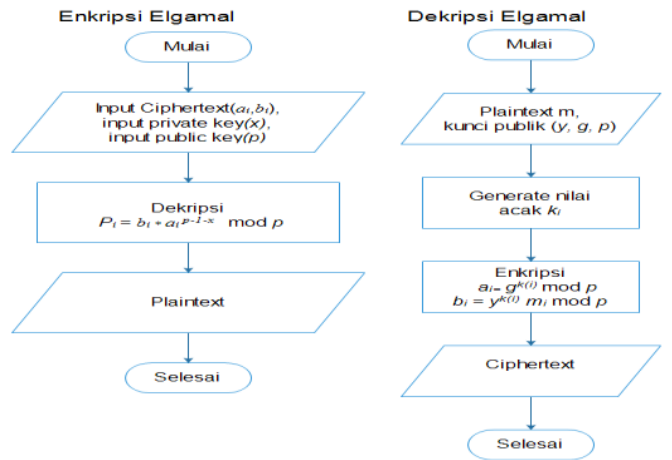

Gambar 2.4 Flowchart Enkripsi Dekripsi ElGamal

\section{HASIL DAN PEMBAHASAN}

\subsection{Implementasi Sistem}

Pada sistem yang dibangun ini terdapat beberapa tab page, yaitu : tabpage Beranda, tabpage Panduan, tabpage Enkripsi Audio, tabpage Pembangkit Kunci, tabpage Enkripsi Kunci OTP, tabpage Dekripsi Kunci OTP, tabpage Dekripsi Audio, tabpage Kirim File.

\subsection{Diskusi Sistem}

1. Diskusi Enkripsi Algoritma One-Time Pad(OTP):

a)pembacaan file audio

Diskusi yang dilakukan pada sistem ini adalah mengenkripsi dan mendekripsi file audio .wav 8-bit mono channel yang berukuran 56 byte yang dapat dilihat pada gambar 8 . 


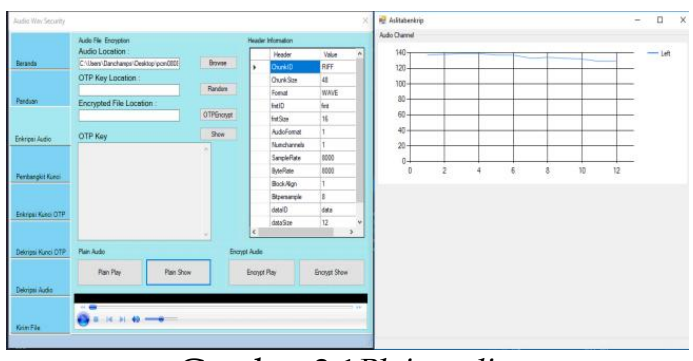

Gambar 3.1Plainaudio

Dari gambar 5 dapat dilihat contoh data fileaudio yang diinputkan di tampilkan dalam bentuk chart. Data fileaudio yang telah diuji ditunjukan dalam bentuk bilangan integer yang dapat dilihat pada tabel 1

Tabel 1 Hasil pembacaan data plainaudio

b) Pembangkitan Kunci One-Time Pad(OTP)

\begin{tabular}{|c|c}
\hline Index & Nilai \\
\hline 1 & 137 \\
\hline 2 & 139 \\
\hline 3 & 139 \\
\hline 4 & 139 \\
\hline 5 & 137 \\
\hline 5 & 137 \\
\hline 7 & 133 \\
\hline 8 & 134 \\
\hline 9 & 133 \\
\hline 10 & 132 \\
\hline 11 & 129 \\
\hline 12 & 129 \\
\hline
\end{tabular}

Adapun proses pembangkitan kunci One-Time Pad dibangkitkan secara acak sepanjang data plainaudio. Berikut merupakan hasil pembangkitan kunci pada tabel 2

Tabel 2 Hasil Pembangkitan Kunci OTP.

\begin{tabular}{|l|l|}
\hline Index & Nilai \\
\hline 1 & 72 \\
\hline 2 & 82 \\
\hline 3 & 21 \\
\hline 4 & 94 \\
\hline 5 & 220 \\
\hline 6 & 3 \\
\hline 7 & 77 \\
\hline 8 & 98 \\
\hline 9 & 226 \\
\hline 10 & 90 \\
\hline 11 & 80 \\
\hline 12 & 101 \\
\hline
\end{tabular}


c) Diskusi enkripsi file audio dengan One-Time Pad

Hasil enkripsi ini didapat dari proses perhitungan algoritma One-

Time Pad yaitu $(\mathrm{Ci}=\mathrm{Pi} \oplus \mathrm{Ki})$.

Contoh Proses enkripsi pada indeks 1:

-Pengirim mengambil data pesan audio $(\mathrm{P} 1)=137$.

-Pengirim mengambil nilai Kunci One-Time Pad (K1) = 72 .

-Pengirim melakukan proses enkripsi:

$-(\mathrm{C} 1)=137 \oplus 72$

$-(\mathrm{C} 1)=193$

Hasil enkripsi perhitungan selengkapnya dapat dilihat pada tabel 3

Tabel 3 Hasil Enkripsi data plainaudio

\begin{tabular}{|c|c|c|c}
\hline Indeks & $\begin{array}{c}\text { Data Audio Asli } \\
\left\{P_{i}\right\}\end{array}$ & $\begin{array}{c}\text { Kunci One- } \\
\text { Time Padi } \\
\text { Ki) }\end{array}$ & $\begin{array}{c}\text { Audio } \\
\text { Terenkripsi } \\
\left(=P_{i} \oplus K_{j}\right.\end{array}$ \\
\hline 1 & 137 & 72 & 193 \\
\hline 2 & 138 & 82 & 216 \\
\hline 3 & 139 & 21 & 158 \\
\hline 4 & 139 & 94 & 213 \\
\hline 5 & 137 & 220 & 85 \\
\hline 6 & 137 & 3 & 138 \\
\hline 7 & 133 & 77 & 200 \\
\hline 8 & 134 & 98 & 228 \\
\hline 9 & 133 & 226 & 103 \\
\hline 10 & 132 & 90 & 222 \\
\hline 11 & 129 & 80 & 209 \\
\hline 12 & 129 & 101 & 228 \\
\hline
\end{tabular}

2. Diskusi Enkripsi Algoritma ElGamal

Dimulai dengan menerima kunci public yang dikirim oleh penerima. Kemudian membaca isi file kunci One-Time Pad yang nilainya dijelaskan pada tabel 2. Dilakukanlah proses enkripsi ElGamal menjadi kedalam dua block yaitu block ai dan block bi.

Berikut contoh perhitungan manual algoritma ElGamal :

-Pengirim pesan menerima kunci public $\mathrm{p}=257371$, $\mathrm{g}=208475, \mathrm{y}=91879$.

-Pengirim pencacah pesan pada audio seperti pada table 2.

-Pengirim pesan memilih bilangan $\mathrm{k}$ secara acak yang relatif prima dengan $\mathrm{p} \mathrm{k1}=99821$.

-Pengirim akan mengenkripsi pesan pada indeks $1 \mathrm{~m} 1=72$.

-Pengirim melakukan proses enkripsi menjadi block a1 dan block b1.

- a1 = gk mod p

- a1 = $20847599821 \bmod 257371$

- a1 $=72053$

- b1 = yk m mod p 
- b1 $=9187999821 * 72 \bmod 257371$

- b1 = 103963

Maka dari hasil perhitungan manual didapatkanlah hasil dari enkripsi algoritma ElGamal yaitu a1 = 72053 dan b1 = 103963 dan pesan inilah yang akan dikirim kepada penerima pesan. Untuk proses perhitungan manual selengkapnya dapat dilihat pada tabel 4

Tabel 4 Hasil Perhitungan Enkripsi Algoritma ElGamal

\begin{tabular}{|l|l|l|l|l|}
\hline $\begin{array}{l}\text { Index( } \\
i)\end{array}$ & $\begin{array}{l}\text { Plaintex } \\
\mathrm{t}(m)\end{array}$ & $k_{i}$ & $\begin{array}{l}\text { Ciphertext } \\
1\left(a_{i}\right) \\
a_{i}=g^{k} \bmod \\
p\end{array}$ & $\begin{array}{l}\text { Ciphertext } \\
2\left(b_{i}\right) \\
b_{i}=y^{k} m \\
\bmod p .\end{array}$ \\
\hline 1 & 72 & 99821 & 72053 & 103963 \\
\hline 2 & 82 & 257261 & 43609 & 107278 \\
\hline 3 & 21 & 61183 & 162542 & 113545 \\
\hline 4 & 94 & 199909 & 31160 & 246981 \\
\hline 5 & 220 & 84557 & 132010 & 97326 \\
\hline 6 & 3 & 218291 & 61502 & 95328 \\
\hline 7 & 77 & 41533 & 88884 & 150684 \\
\hline 8 & 98 & 225311 & 119421 & 234456 \\
\hline 9 & 226 & 118813 & 252156 & 55086 \\
\hline 10 & 90 & 215959 & 89930 & 110908 \\
\hline & & & &
\end{tabular}

\section{Diskusi Dekripsi Algoritma ElGamal}

Pada algoritma ElGamal proses dekripsi dilakukan dengan menggabungkan block $a_{i}$ dan block $b_{i}$ menjadi pesan asli kembali $m_{i}$ denganmenggunakan kunci private yang telah dibangkitkan dan bilangan prima $p$ yang terdapat pada kunci public. Setelah itu dilakukan proses dekripsi dengan menggunakan algoritma ElGamal. Berikut contoh perhitungan manual proses dekripsi algoritma ElGamal pada indeks 1 :

-Penerima mengambil nilai kunci private yang telah dibangkitkan $x=130285$.

-Penerima mengambil nilai bilangan prima pada kunci

publicp $=257371$.

-Penerima mengambil nilai blocka $1=72053$.

-Penerima mengambil nilai block $b_{1}=103963$.

-Penerima menghitung nilai pesan dengan algoritma

ElGamal.

$-m_{i}=b / a^{x} \bmod p$ 
$-m_{1}=103963 / 72053^{130285} \bmod 257371$

$-m_{1}=72$

Hasil perhitungan manual algoritma ElGamal secara keseluruhan dapat dilihat pada tabel 5 .

Tabel 5 Hasil Perhitungan Dekripsi Algoritma ElGamal.

\begin{tabular}{|l|l|l|l|}
\hline $\begin{array}{l}\text { Index } \\
\text { I) }\end{array}$ & $\begin{array}{l}\text { Ciphert } \\
\text { ext1 }\left(a_{i}\right)\end{array}$ & $\begin{array}{l}\text { Ciphert } \\
\text { ext2 }\left(b_{i}\right)\end{array}$ & $\begin{array}{l}\text { Dekrip } \\
\text { si }(m) \\
m_{i}=b / \\
a^{x} \text { mod } \\
p\end{array}$ \\
\hline 1 & 72053 & 103963 & 72 \\
\hline 2 & 43609 & 107278 & 82 \\
\hline 3 & 162542 & 113545 & 21 \\
\hline 4 & 31160 & 246981 & 94 \\
\hline 5 & 132010 & 97326 & 220 \\
\hline 6 & 61502 & 95328 & 3 \\
\hline 7 & 88884 & 150684 & 77 \\
\hline 8 & 119421 & 234456 & 98 \\
\hline 9 & 252156 & 55086 & 226 \\
\hline 10 & 89930 & 110908 & 90 \\
\hline 11 & 188408 & 86840 & 80 \\
\hline 12 & 92304 & 21453 & 101 \\
\hline
\end{tabular}

4. Diskusi Dekripsi Algoritma One-Time Pad

Setelah didapatkan file kunci OTP yang telah didekripsi, maka penerima pesan dapat melakukan proses dekripsi terhadap fileaudio yang terenkripsi. Pada proses dekripsi fileaudio yang terenkripsi penerima pesan menginputkan fileaudio yang akan didekripsi, kemudian menginputkan file kunci OTP yang telah didekripsi. Proses dekripsi dilakukan dengan cara melakukan perhitungan XOR terhadap file audio yang terenkripsi dan file kunci OTP yang akan menghasilkan file audio asli. Berikut contoh perhitungan manual proses dekripsi algoritma OneTime Pad pada indeks 1:

-Penerima mengambil nilai cipheraudio $C_{1}=193$.

-Penerima mengambil nilai kunci OTP $K_{1}=72$.

-Penerima melakukan proses dekripsi menggunakan

$P_{i}=C_{i} \oplus K_{i}$.

$-\left(P_{1}\right)=137 \oplus 72$

$-\left(P_{1}\right)=193$ 
Perhitungan manual proses dekripsi algoritma One-Time Pad secara keseluruhan dapat dilihat pada tabel 6 .

Tabel 6 Hasil Perhitungan Dekripsi FileAudio.

\begin{tabular}{|l|l|l|l|}
\hline Indeks $i$ & $\begin{array}{l}\text { Kunci } \\
\text { One-Time } \\
\text { Pad }\left(K_{i}\right)\end{array}$ & $\begin{array}{l}\text { Audio } \\
\text { Terenkripsi } \\
\left(C_{i}\right)\end{array}$ & $\begin{array}{l}\text { Data Audio } \\
\text { Asli } \\
\left(P_{i}=C_{i} \oplus K_{i}\right)\end{array}$ \\
\hline 1 & 72 & 193 & 137 \\
\hline 2 & 82 & 216 & 138 \\
\hline 3 & 21 & 158 & 139 \\
\hline 4 & 94 & 213 & 139 \\
\hline 5 & 220 & 85 & 137 \\
\hline 6 & 3 & 138 & 137 \\
\hline 7 & 77 & 200 & 133 \\
\hline 8 & 98 & 228 & 134 \\
\hline 9 & 226 & 103 & 133 \\
\hline 10 & 90 & 222 & 132 \\
\hline 11 & 80 & 209 & 129 \\
\hline 12 & 101 & 228 & 129 \\
\hline
\end{tabular}

\section{Diskusi Algoritma Terhadap Waktu Proses}

Salah satu parameter Diskusi dalam penitian ini adalah Diskusi terhadap waktu proses enkripsi dan proses dekripsi.

a) Diskusi Enkripsi file audio dengan algoritma OTP

Hubungan waktu proses enkripsi file audio terhadap ukuran suatu file audio dapat dilihat pada tabel 7 dan gambar 6

Tabel 7 Hasil Diskusi Waktu Proses Enkripsi Audio

\begin{tabular}{|l|l|l|l|l|}
\hline \multirow{2}{*}{$\begin{array}{l}\text { Besar } \\
\text { File(KB) }\end{array}$} & \multicolumn{4}{|l|}{ Waktu Proses (ms) } \\
\cline { 2 - 5 } & $\begin{array}{l}\text { Percobaa } \\
\text { n 1 }\end{array}$ & $\begin{array}{l}\text { Percobaa } \\
\text { n 2 }\end{array}$ & $\begin{array}{l}\text { Percobaa } \\
\text { n 3 }\end{array}$ & $\begin{array}{l}\text { Rata- } \\
\text { rata }\end{array}$ \\
\hline \pm 1 & 2 & 2 & 2 & 2 \\
\hline \pm 10 & 9 & 9 & 9 & 9 \\
\hline \pm 100 & 14 & 14 & 14 & 14 \\
\hline \pm 1000 & 72 & 72 & 72 & 72 \\
\hline \pm 10000 & 670 & 670 & 673 & 671 \\
\hline
\end{tabular}




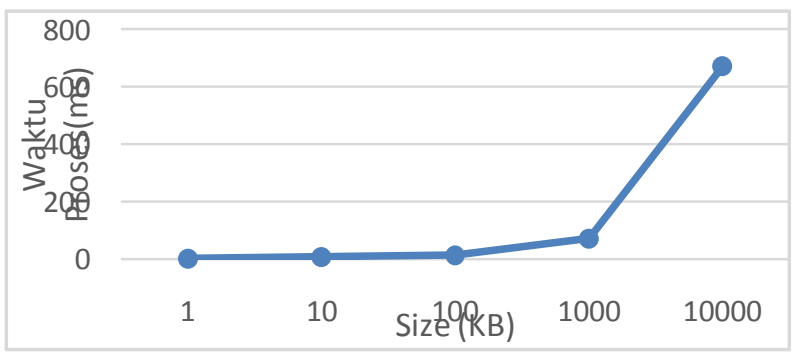

Gambar 3.2 Chart Waktu Proses Enkripsi Algoritma OTP

b) Diskusi Dekripsi file audio dengan algoritma OTP

Hubungan waktu proses enkripsi file audio terhadap ukuran suatu file audio dapat dilihat pada tabel 8 dan gambar 11 .

Tabel 8 HasilDiskusi Waktu Proses Dekripsi FileAudio

\begin{tabular}{|l|l|l|l|l|}
\hline \multirow{2}{*}{$\begin{array}{l}\text { Besar } \\
\text { File }(\mathrm{KB}\end{array}$} & \multicolumn{4}{|l|}{ Waktu Proses $(\mathrm{ms})$} \\
\cline { 2 - 5 } & $\begin{array}{l}\text { Percobaan } \\
1\end{array}$ & $\begin{array}{l}\text { Percobaan } \\
2\end{array}$ & $\begin{array}{l}\text { Percobaan } \\
3\end{array}$ & $\begin{array}{l}\text { Rata- } \\
\text { rata }\end{array}$ \\
\hline \pm 1 & 2 & 2 & 2 & 2 \\
\hline \pm 10 & 9 & 9 & 9 & 9 \\
\hline \pm 100 & 14 & 14 & 14 & 14 \\
\hline \pm 1000 & 72 & 72 & 72 & 72 \\
\hline \pm 10000 & 670 & 668 & 674 & 670.6 \\
\hline
\end{tabular}

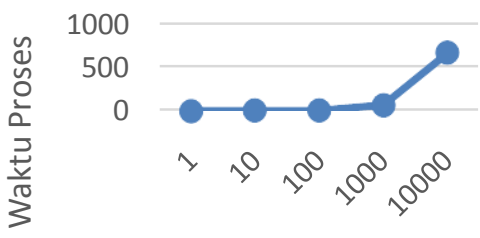

Size (KB)

Gambar 7Chart Waktu Proses Dekripsi Algoritma OTP

c)Diskusi Enkripsi File Kunci OTP dengan Algoritma ElGamal

Hubungan waktu proses enkripsi file kunci OTP terhadap ukuran suatu file audio dapat dilihat pada tabel 9 dan gambar 8 
Tabel 9 HasilDiskusi Waktu Proses Enkripsi File Kunci OTP.

\begin{tabular}{|l|l|l|l|l|}
\hline $\begin{array}{l}\text { Besar File } \\
\text { Kunci } \\
\text { OTP(KB) }\end{array}$ & \multicolumn{2}{|l|}{ Waktu Proses (ms) } \\
\cline { 2 - 5 } & $\begin{array}{l}\text { Percobaa } \\
\text { n 1 }\end{array}$ & $\begin{array}{l}\text { Percobaa } \\
\text { n 2 }\end{array}$ & $\begin{array}{l}\text { Percobaa } \\
\text { n 3 }\end{array}$ & $\begin{array}{l}\text { Rata- } \\
\text { rata }\end{array}$ \\
\hline \pm 4 & 21 & 21 & 21 & 21 \\
\hline \pm 40 & 74 & 74 & 74 & 74 \\
\hline \pm 400 & 678 & 675 & 678 & 677 \\
\hline \pm 4000 & 6614 & 6595 & 6595 & 6601.3 \\
\hline \pm 40000 & 53751 & 54201 & 53118 & 53690 \\
\hline
\end{tabular}

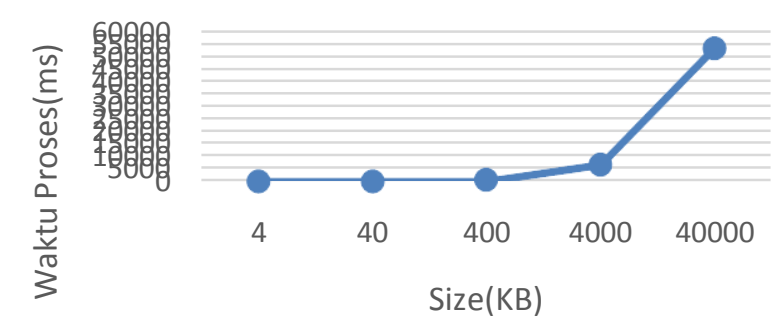

Gambar 3.3 Chart Waktu Proses Enkripsi Algoritma ElGamal.

d)Diskusi Dekripsi File Kunci OTP dengan Algoritma ElGamal

Hubungan waktu proses enkripsi file kunci OTP terhadap ukuran suatu file audio dapat dilihat pada tabel 10 dan gambar 9 .

Tabel 10 HasilDiskusi Waktu Proses Dekripsi File Kunci OTP.

\begin{tabular}{|l|l|l|l|l|}
\hline \multirow{2}{*}{$\begin{array}{l}\text { Besar } \\
\text { File } \\
\text { kunci }\end{array}$} & \multicolumn{4}{|l|}{ Waktu Proses (ms) } \\
\cline { 2 - 5 } & $\begin{array}{l}\text { Percobaan } \\
1\end{array}$ & $\begin{array}{l}\text { Percobaan } \\
2\end{array}$ & $\begin{array}{l}\text { Percobaan } \\
3\end{array}$ & $\begin{array}{l}\text { Rata- } \\
\text { rata }\end{array}$ \\
\hline \pm 14 & 8 & 8 & 8 & 8 \\
\hline \pm 140 & 45 & 45 & 45 & 45 \\
\hline \pm 1400 & 344 & 344 & 344 & 344 \\
\hline \pm 14000 & 2828 & 2807 & 2796 & 2810.3 \\
\hline \pm 140000 & 25409 & 25483 & 25514 & 25468 \\
\hline
\end{tabular}




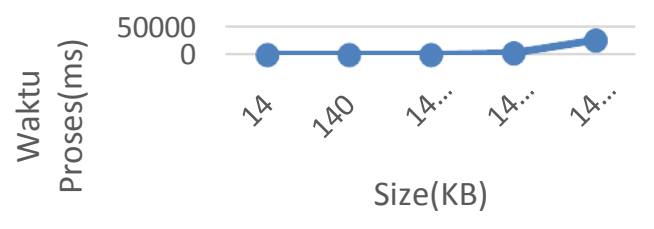

Gambar 3.4 Chart Waktu Proses Dekripsi Algoritma ElGamal.

\section{KESIMPULAN}

1. Implementasi kriptografi hibrid dari kedua algoritma berhasil diterapkan dan hasil diskusi pada sistem didapatkan bahwa file audio yang telah mengalami proses enkripsi dan proses dekripsi dengan algoritma One-Time Pad memiliki isi informasi yang sama dengan file audio yang asli.

2. Hasil diskusi pada sistem didapatkan bahwa pengkombinasian algoritma ElGamal dan One-Time Pad tidak efisien dikarenakan file kunci OTP terenkripsi memiliki ukuran data yang lebih besar dibanding file audio yang terenkripsi yang artinya pengiriman file kunci dan file audio serta proses enkripsi dan proses dekripsi akan membutuhkan waktu yang sangat lama.

\section{DAFTAR PUSTAKA}

Iqbal, M \& Pane, M. A. S. 2016. SMS Encryption Using One-Time Pad Cipher. IOSR Journal of Computer Engineering (IOSR-JCE) Volume 18, No. 6: 54-58.

Ramadayanti, A. L. 2008. Analisa algoritma Vernam (OTP). Skripsi. Universitas Sriwijaya.

Riyanto, M. Z. 2007. Pengamanan Pesan Rahasia Menggunakan Algoritma ElGamal Atas Grup Pergandaan $Z_{\mathrm{p}}{ }^{*}$. Skripsi. Universitas Gadjah Mada.

Rolf, O. 2011. Contemporary Cryptography. 2nd Edition. Artech House: Norwood.

Salomon, D. 2007. Data Compression: The Complete Reference. $4^{\text {th }}$ Edition.Springer- Verlag: London.

Zelvina, A., Efendi, S. \& Arisandi, D. 2012. Perancangan Aplikasi Pembelajaran Kriptografi Kunci Publik ElGamal Untuk Mahasiswa. Jurnal Dunia Teknologi Informasi Volume 1, No. 1: 56-62. 